\title{
Deep brain stimulation versus pallidotomy for status dystonicus: a single-center case series
}

\author{
*Vincenzo Levi, MD,,2,2 Giovanna Zorzi, MD, ${ }^{3}$ Giuseppe Messina, MD, ${ }^{1}$ Luigi Romito, MD, ${ }^{4}$ \\ Irene Tramacere, PhD, ${ }^{5}$ Ivano Dones, MD, ${ }^{1}$ Nardo Nardocci, MD, ${ }^{3}$ and Angelo Franzini, MD' \\ ${ }^{1}$ Neurosurgery Department, Functional Neurosurgery Unit, Fondazione IRCCS Istituto Neurologico Carlo Besta; ${ }^{2}$ Department \\ of Electronics, Information and Bioengineering, Polytechnic University of Milan; ${ }^{3}$ Pediatric Neuroscience Department, Child \\ Neuropsychiatry Unit, Fondazione IRCCS Istituto Neurologico Carlo Besta; ${ }^{4}$ Neurology Department, Movement Disorders \\ Unit, Fondazione IRCCS Istituto Neurologico Carlo Besta; and ${ }^{5}$ Department of Research and Clinical Development, Scientific \\ Directorate, Fondazione IRCCS Istituto Neurologico Carlo Besta, Milan, Italy
}

OBJECTIVE First-line pharmacological therapies have shown limited efficacy in status dystonicus (SD), while surgery is increasingly reported as remediable in refractory cases. In this context, there is no evidence regarding which neurosurgical approach is the safest and most effective. The aim of this study was to assess the clinical outcomes and surgeryrelated complications of globus pallidus internus deep brain stimulation (GPi DBS) and pallidotomy for the treatment of drug-resistant SD.

METHODS The authors reviewed the records of patients with drug-resistant SD who had undergone GPi DBS or pallidotomy at their institution between 2003 and 2017. The severity of the dystonia was evaluated using the Barry-Albright Dystonia (BAD) Scale. Surgical procedures were performed bilaterally in all cases.

RESULTS Fourteen patients were eligible for inclusion in the study. After surgery, the mean follow-up was $40.6 \pm 30$ months. DBS ended the dystonic storm in $87.5 \%$ of cases $(7 / 8)$, while pallidotomy had a success rate of $83.3 \%(5 / 6)$. No significant differences were observed between the two techniques in terms of failure rates (risk difference DBS vs pallidotomy $-0.03,95 \% \mathrm{Cl}-0.36$ to 0.30 ), SD mean resolution time (DBS $34.8 \pm 19$ days, pallidotomy $21.8 \pm 20.2$ days, $p>0.05)$, or BAD scores at each postoperative follow-up ( $>0.05)$. The long-term hardware complication rate after DBS was $37.5 \%$, whereas no surgery-related complications were noted following pallidotomy.

CONCLUSIONS The study data suggest that DBS and pallidotomy are equally safe and effective therapies for drugresistant SD. The choice between the two techniques should be tailored on a case-by-case basis, depending on factors such as the etiology and evolution pattern of the underlying dystonia and the clinical conditions at the moment of SD onset. Given the limitation of the low statistical power of this study, further multicentric investigations are needed to confirm its findings.

https://thejns.org/doi/abs/10.3171/2019.10.JNS191691

KEYWORDS deep brain stimulation; DBS; pallidotomy; status dystonicus; dystonia; dystonic storm; ablative surgery; functional neurosurgery

$\mathrm{S}$ TATUS dystonicus (SD) is a rare but life-threatening movement disorder emergency characterized by severe episodes of generalized or focal dystonia potentially accompanied by other hyperkinetic movements that have necessitated urgent hospitalization, regardless of the patient's neurological condition at baseline. ${ }^{24,26,29}$ Also known as "dystonic storm," SD is frequently reported in children and can be triggered by several precipitating factors, such as infections, drug withdrawal, and surgical procedures. ${ }^{1,25}$ Early recognition and intervention are paramount in cases of SD, as its persistence often leads to serious sequelae, such as rhabdomyolysis and respiratory failure, with consequent high mortality rates $(10 \%-15 \%) .,{ }^{1,27}$

There is still no consensus on the optimal strategy for treating SD. Antidystonic drugs and profound sedation usually represent the first therapeutic options. Unfortunately, their efficacy is limited and surgical alternatives are needed in the majority of cases. ${ }^{15}$ An increasing number

ABBREVIATIONS AC-PC = anterior commissure-posterior commissure; BAD = Barry-Albright Dystonia; DBS = deep brain stimulation; GPi = globus pallidus internus; ITB = intrathecal baclofen; MNI = Montreal Neurological Institute; SD = status dystonicus; $S P$ = staged pallidotomy.

SUBMITTED June 18, 2019. ACCEPTED October 3, 2019.

INCLUDE WHEN CITING Published online December 20, 2019; DOI: 10.3171/2019.10.JNS191691.

* V.L. and G.Z. share first authorship, and N.N. and A.F. share senior authorship. 
of clinical studies have shown the effectiveness of deep brain stimulation (DBS) of the globus pallidus internus (GPi) in cases of drug-resistant SD. $5,6,23,32,37,42,44,45$ However, one shortcoming of DBS is the nonnegligible risk of hardware-related complications in the pediatric dystonia population..$^{28}$ In addition, several reports have described the onset of severe or fatal SD as a consequence of a DBS depleted battery or lead dislocation. ${ }^{34-36}$ Also, DBS may not be effective in resolving SD. In a recent study by Nerrant et al., 2 patients died as a direct consequence of refractory $\mathrm{SD}$, despite attempts at subsequent rescue DBS therapy. ${ }^{32}$ In this context, ablative procedures such as pallidotomy, which does not require any hardware implantation, are likely to be of benefit. However, their effectiveness for SD has been reported in only sporadic case reports and small case series. ${ }^{8,9,14,17,28,33}$

The primary aim of the present study was to compare the clinical outcomes and surgery-related complication rates of pallidotomy and GPi DBS for the treatment of SD in a single-center cohort. Potential correlations among SD characteristics, type of neurosurgical treatment, and outcomes were then analyzed and discussed.

\section{Methods \\ Study Design and Data Collection}

The records of patients with drug-resistant SD who had undergone GPi DBS or pallidotomy at our institution between 2003 and 2017 were reviewed. All the surgical procedures were performed in accordance with the 1964 Declaration of Helsinki and its later amendments. Patients or their relatives provided written informed consent in all cases.

Inclusion criteria for drug-resistant SD included patients of any age with abrupt exacerbation of the baseline dystonic phenomenology, unresponsiveness to at least 2 antidystonic medications, urgent intensive care unit (ICU) admission with profound sedation, and at least one of the Manji diagnostic criteria (Table 1) ${ }^{26}$ Discharge from the ICU was chosen as the event indicative of the end of the dystonic storm. The following data were collected: patient demographics, baseline dystonia characteristics (age, sex, dystonia etiology, age at onset of dystonia, disease duration before SD, trigger factors), and hospital course (medications, time between SD onset and surgery, type of surgery, $\mathrm{SD}$ resolution or persistence, complications). Dystonia severity was evaluated according to the Barry-Albright Dystonia (BAD) Scale at the last available visit before onset of the dystonic storm (baseline BAD), during the storm (SD BAD), 1 month after surgery (postoperative BAD), and at the last available follow-up (last BAD). ${ }^{39}$ Clinical outcomes at 1 month after surgery were categorized according to a modified Ben-Haim scale (Table 1) ${ }^{6}$ During telephone interviews conducted in June 2018, all caregivers rated their experience with long-term caregiving and patient comfort levels after surgery by using a subjective rating scale (Table 1).

\section{Surgical Procedures GPi DBS}

GPi DBS was usually considered the first surgical

\section{TABLE 1. Various scales used in the study}

\begin{tabular}{l}
\hline Manji diagnostic criteria \\
\hline Bulbar weakness compromising upper airway patency \\
\hline Physical exhaustion \& pain \\
\hline Metabolic imbalances such as myoglobinuria \\
\hline Renal or respiratory failure \\
\hline Modified Ben-Haim scale \\
\hline 1, death \\
\hline 2, SD resolution w/ deterioration from baseline dystonia (BAD \\
increase $>25 \%)$ \\
\hline 3, SD resolution but w/ unchanged baseline dystonia (BAD variation \\
btwn $\pm 25 \%)$ \\
\hline 4, SD resolution w/ slight improvement of baseline dystonia (BAD \\
reduction $>25 \%$ but $<50 \%)$ \\
\hline 5, SD resolution w/ great improvement of baseline dystonia (BAD \\
reduction $\geq 50 \%)$ \\
\hline Subjective caregiver benefit scale \\
\hline-1, worse than expected \\
\hline 0, no benefit \\
\hline 1, minimal benefit \\
\hline 2, good benefit, as expected \\
\hline 3, excellent benefit, more than expected
\end{tabular}

option in patients with a good nutritional state and progressive baseline dystonia course. Surgery was always performed under general anesthesia, bilaterally, and under stereotactic conditions with the Leksell (Elekta Inc.) or Maranello (Eidos22) frame. Our routine surgical procedure has been extensively discussed elsewhere. ${ }^{16} \mathrm{GPi}$ coordinates related to the anterior commissure-posterior commissure (AC-PC) midpoint were set at X $( \pm 19), \mathrm{Y}(+2)$, and $\mathrm{Z}(-6)$ in all cases.

\section{Conventional and Staged Pallidotomy}

Conventional pallidotomy was routinely performed under general anesthesia and in stereotactic conditions for the following indications: 1) previous DBS failure, 2) patients with a high risk for DBS hardware-related complications (e.g., those having a low body weight, severe malnutrition, or poor skin condition), and 3) patients who were not usually considered good DBS candidates at our institution because of poor expected responsiveness to stimulation (severe acquired dystonia characterized by a long, static disease course and by the absence of a period of normal development). Based on previous studies of pallidotomies, ablation was performed in the midportion of the GPi, which is still part of the posteroventral GPi. ${ }^{10,28}$ This targeting technique, in which the target was always defined using direct visualization on preoperative images given the frequent anatomy distortion in these patients, allows for immediate benefit for dystonic symptoms, without preventing patients from receiving further gain from subsequent DBS of the most posterior part of the GPi. ${ }^{28}$

The radiofrequency monopolar lesions were always created bilaterally at the target, $2 \mathrm{~mm}$ above it, and 2 $\mathrm{mm}$ below it, through a CSK-TC20 electrode (Cosman Medical; 4-mm exposed uninsulated tip, $1 \mathrm{~mm}$ in diam- 
eter) with a 60 -second train of $40 \mathrm{~V}$ through the radiofrequency generator, reaching a temperature of $70^{\circ} \mathrm{C}$. The heat generated during the lesioning process was usually monitored, with a thermistor recording the temperature at the probe tip. Microrecording and macrostimulation were performed under electromyography monitoring to exclude involvement of pyramidal fibers of the internal capsule by the lesioning.

More recently, bilateral staged pallidotomy (SP) has been gradually introduced at our institution. Quadripolar DBS leads (3389, Medtronic) are used to generate the ablation by connecting their extracranial termination to a radiofrequency generator (RFG-1A, Cosman Medical). ${ }^{4,18}$ SP can be used de novo, as a salvage treatment after previous DBS failure, or prior to lead removal because of DBS hardware infection. Its main advantages include the possibility of checking the definitive electrode location prior to lesioning and monitoring ablation evolution over time. ${ }^{18}$ The lesion is usually created in a bipolar fashion between lead central contacts 2 days after surgery with a 40 -second train of $40 \mathrm{~V}$. If needed, the ablation can be easily repeated in the following days. Once the pallidotomy effect is achieved, leads can be left in place (should the patient need DBS in the future) or removed.

\section{Postoperative Lead and Lesion Localization}

In the case of DBS or SP, the postoperative CT scan was merged with the preoperative MR image (Framelink, Medtronic) to assess the definitive lead location in the ACPC space. Final coordinates were identified as the center of the beam-hardening artifact representing the deepest contact (contact 0 ). The position in the Montreal Neurological Institute (MNI) space of all DBS leads was also detected and reconstructed three-dimensionally by using the Lead-DBS MATLAB toolbox. ${ }^{20}$

In cases of conventional pallidotomy, lesion location was evaluated in the AC-PC space by merging the postoperative MR image (usually obtained within 1 week after surgery) with the preoperative volumetric CT scan. The center of the lesion was identified in the axial slice in which the lesion had the largest diameter.

\section{Statistical Analysis}

Descriptive statistics were provided as percentages for dichotomous data and the mean \pm standard deviation for continuous data. Preoperative differences between patients who had undergone DBS and those who had been treated with pallidotomy were evaluated using unpaired t-tests. Differences between SD BAD and postoperative BAD scores were assessed using paired t-tests. Repeated measures ANOVA was used to compare postoperative BAD scores between DBS and pallidotomy groups. Pearson correlation coefficients were used to assess significant associations between the effect of surgery (in terms of the difference between SD BAD score and postoperative BAD score) and baseline dystonia duration or time spent in SD before the final surgery. Statistical analyses were performed using Stata statistical software (release 15, 2017, StataCorp LLC). Statistical significance was set at $\mathrm{p} \leq 0.05$.

\section{Results \\ Patient Demographics and Baseline Characteristics}

Demographic data and baseline dystonia characteristics are shown in Table 2. Fourteen patients fulfilled the inclusion criteria for the study. The cohort included 12 pediatric and 2 adult patients. Three patients (21.4\%) experienced a prior SD episode, which had been successfully managed with antidystonic drugs. Dystonia etiology was identified in all but 1 case.

All patients had severe generalized dystonia and were on oral antidystonic treatment prior to the onset of SD; 4 of them also had an intrathecal baclofen (ITB) pump. The mean baseline BAD score before the onset of SD was 21.8 \pm 3.6 points.

\section{Characteristics of the Dystonic Storms}

The mean age at SD onset was $11.8 \pm 5$ years. The temporal course of SD onset ranged from days to weeks in $85.7 \%(12 / 14)$ of patients, whereas slow worsening of dystonia over a few months was documented in 2 subjects, one affected by a GNAO1 encephalopathy and one suffering from a dyskinetic cerebral palsy (2/14 [14.3\%]). Triggering factors were identified in 50\% (7/14) of cases (Table 2). Among those patients with an ITB pump, 2 developed SD as a consequence of ITB-related adverse events (1 malfunction and 1 infection), while ITB malfunction was ruled out in the remaining cases.

The mean SD duration was $74.6 \pm 55$ days. The mean SD BAD score was $31.2 \pm 0.8$ points. No significant preoperative differences were found between patients who underwent DBS and those who were treated with pallidotomy in terms of age at dystonia onset, age at SD onset, duration of dystonia, time between SD onset and surgery, baseline BAD scores, and SD BAD scores (all p >0.05).

\section{Clinical Outcomes}

The mean dystonia duration before surgery was $7.8 \pm$ 4.1 years, while the mean time from SD onset to surgery was $30.3 \pm 20.3$ days. After surgery, the total BAD scores were significantly improved both at 1 month (mean postoperative BAD score $24.9 \pm 6.7, \mathrm{p}<0.01$ ) and at the last follow-up (mean last BAD score $28 \pm 4.8, \mathrm{p}<0.01$; mean follow-up $40.6 \pm 30$ months) as compared to the total SD BAD scores (mean $31.3 \pm 0.8$; Table 3 ). The effect of surgery was not correlated with baseline dystonia duration $(r=0.17, p>0.05)$ or time spent in SD before the final surgery $(r=0.19, p>0.05)$. Overall clinical outcomes categorized according to the modified Ben-Haim scale at the 1-month follow-up and the subjective benefit reported by caregivers are shown in Fig. 1. No further SD recurrence was noted during follow-up. Mortality as a direct consequence of an SD episode was $7.1 \%$ (1/14), while 2 other patients (2/14 [14.3\%]) died during follow-up due to complications indirectly related to the underlying dystonia. They both suffered from a severe form of pneumonia evolving into sepsis.

\section{Deep Brain Stimulation}

Bilateral GPi DBS was performed in 8 patients, ending 
Levi et al.

TABLE 2. Patient demographics, baseline dystonia characteristics, and initial drug treatment for SD

\begin{tabular}{|c|c|c|c|c|c|c|c|c|c|}
\hline $\begin{array}{l}\text { Case } \\
\text { No. }\end{array}$ & Sex & $\begin{array}{c}\text { Age at } \\
\text { Diagnosis } \\
\text { (yrs) }\end{array}$ & $\begin{array}{l}\text { Dystonia } \\
\text { Etiology }\end{array}$ & Dystonia Course & $\begin{array}{c}\text { Baseline } \\
\text { BAD } \\
\text { Score }\end{array}$ & $\begin{array}{l}\text { Age } \\
\text { at SD } \\
\text { Onset } \\
\text { (yrs) }\end{array}$ & $\begin{array}{l}\text { Trigger } \\
\text { Factors }\end{array}$ & $\begin{array}{c}\text { SD } \\
\text { Phenomenology }\end{array}$ & Initial Pharmacological Treatment \\
\hline 1 & $\mathrm{~F}$ & 2 & PKAN classic & Progressive & 28 & 10 & $\begin{array}{l}\text { ITB pump } \\
\text { infection }\end{array}$ & Tonic & $\begin{array}{l}\text { Midazolam, propofol, tetrabenazine, } \\
\text { trihexyphenidyl }\end{array}$ \\
\hline 2 & $\mathrm{~F}$ & 4 & Post-infective & Static & 24 & 7 & $\begin{array}{l}\text { Bacterial } \\
\text { infection }\end{array}$ & Tonic & $\begin{array}{l}\text { Midazolam, propofol, tetrabenazine, } \\
\text { oral baclofen }\end{array}$ \\
\hline $3^{*}$ & M & 1 & Unknown & Slow progressive & 22 & 9 & $\begin{array}{l}\text { Pyrexia of } \\
\text { unknown } \\
\text { etiology }\end{array}$ & Phasic & $\begin{array}{l}\text { Phenobarbital, oral baclofen, trihexy- } \\
\text { phenidyl, quetiapine, midazolam }\end{array}$ \\
\hline $4^{*}$ & $\mathrm{~F}$ & 1 & GNA01 & Progressive & 19 & 6 & $\begin{array}{l}\text { Dental infec- } \\
\text { tion }\end{array}$ & Phasic & $\begin{array}{l}\text { Midazolam, tetrabenazine, oral } \\
\text { baclofen }\end{array}$ \\
\hline 5 & M & 2 & PKAN atypical & Static & 22 & 8 & $\begin{array}{l}\text { ITB pump } \\
\text { malfunction }\end{array}$ & Tonic & Midazolam, propofol, tetrabenazine \\
\hline 6 & $\mathrm{~F}$ & 3 & $\mathrm{CP}$ & Static & 20 & 10 & Viral infection & Phasic & $\begin{array}{l}\text { Midazolam, propofol, tetrabenazine, } \\
\text { oral baclofen }\end{array}$ \\
\hline 7 & M & 6 & $\mathrm{CP}$ & Static & 22 & 14 & None & Tonic & Midazolam, propofol, trihexyphenidyl \\
\hline 8 & M & 11 & PKAN classic & Progressive & 12 & 13 & None & Tonic & Midazolam, propofol, trihexyphenidyl \\
\hline 9 & M & 4 & PKAN classic & Progressive & 22 & 9 & None & Tonic & $\begin{array}{l}\text { Midazolam, propofol, tetrabenazine, } \\
\text { oral baclofen }\end{array}$ \\
\hline 10 & $\mathrm{~F}$ & 2 & PKAN classic & Progressive & 21 & 10 & None & Tonic & Midazolam, propofol, tetrabenazine \\
\hline 11 & $\mathrm{~F}$ & 16 & PKAN classic & Progressive & 22 & 24 & Bacterial & Tonic & Midazolam, propofol, tetrabenazine \\
\hline $12 \dagger$ & $\mathrm{F}$ & 1 & $\mathrm{CP}$ & Static & 25 & 19 & None & Phasic & Midazolam, propofol, tetrabenazine \\
\hline $13^{*}$ & $\mathrm{~F}$ & 1 & GNA01 & Progressive & 24 & 10 & None & Phasic & Midazolam, propofol, trihexyphenidyl \\
\hline $14 \dagger$ & $M$ & 2 & $\mathrm{CP}$ & Static & 22 & 16 & None & Tonic & $\begin{array}{l}\text { Midazolam, propofol, thiopentone, } \\
\text { tetrabenazine, trihexyphenidyl }\end{array}$ \\
\hline
\end{tabular}

$\mathrm{CP}=$ cerebral palsy; GNAO1 = guanine nucleotide-binding protein, alpha-activating activity polypeptide O; PKAN = pantothenate kinase-associated neurodegeneration.

* These 3 patients had a previous SD, managed with antidystonic drugs and sedation.

$\dagger$ These 2 patients died during the follow-up due to complications unrelated to their baseline dystonia.

TABLE 3. Surgery for SD and outcomes

\begin{tabular}{|c|c|c|c|c|c|c|c|c|c|c|}
\hline $\begin{array}{l}\text { Case } \\
\text { No. }\end{array}$ & Type of Surgery & $\begin{array}{l}\text { SD } \\
\text { BAD } \\
\text { Score }\end{array}$ & $\begin{array}{l}\text { Postop } \\
\text { BAD } \\
\text { Score }\end{array}$ & $\begin{array}{l}\text { Last } \\
\text { BAD } \\
\text { Score }\end{array}$ & $\begin{array}{l}\text { Time From } \\
\text { SD Onset to } \\
\text { Surgery (days) }\end{array}$ & $\begin{array}{l}\text { SD Resolution After } \\
\text { Surgery (days) }\end{array}$ & $\begin{array}{l}\text { Modified } \\
\text { Ben-Haim } \\
\text { Scale }\end{array}$ & $\begin{array}{c}\text { Caregiver Benefit } \\
\text { Assessment } \\
\text { Scale }\end{array}$ & Complications & $\begin{array}{c}\mathrm{FU} \\
\text { (mos) }\end{array}$ \\
\hline 1 & Pallidotomy & 32 & 32 & NA & 60 & Death after 35 days & 1 & -1 & NA & NA \\
\hline 2 & Pallidotomy & 32 & 29 & 31 & 43 & 1 & 2 & 2 & None & 12 \\
\hline 3 & Staged pallidotomy & 30 & 14 & 15 & 36 & 35 & 4 & 3 & None & 12 \\
\hline 4 & DBS & 32 & 21 & 21 & 15 & 24 & 3 & 2 & None & 12 \\
\hline 5 & Pallidotomy & 31 & 30 & 30 & 3 & 15 & 2 & 0 & None & 12 \\
\hline 6 & DBS & 32 & 22 & 22 & 15 & 33 & 3 & 2 & Lead fracture & 63 \\
\hline 7 & DBS & 31 & 25 & 25 & 40 & 30 & 3 & 3 & Lead fracture & 19 \\
\hline 8 & DBS & 32 & 9 & 24 & 15 & 2 & 4 & 3 & None & 84 \\
\hline 9 & DBS & 31 & 28 & 28 & 15 & 15 & 2 & 2 & None & 36 \\
\hline 10 & DBS & 30 & 28 & 28 & 9 & 40 & 2 & 2 & Lead fracture & 42 \\
\hline 11 & DBS & 32 & 30 & 25 & 63 & 60 & 2 & 2 & None & 28 \\
\hline $12^{*}$ & Pallidotomy & 31 & 24 & 28 & 60 & 50 & 3 & 0 & None & 38 \\
\hline 13 & DBS, pallidotomy & 32 & 28 & 28 & 30 & 60 & 3 & 3 & None & 180 \\
\hline $14^{*}$ & Pallidotomy & 30 & 25 & 28 & 21 & 8 & 3 & 0 & None & 30 \\
\hline
\end{tabular}

$\mathrm{NA}=$ not applicable

* Two patients died during the follow-up due to complications unrelated to their baseline dystonia. 

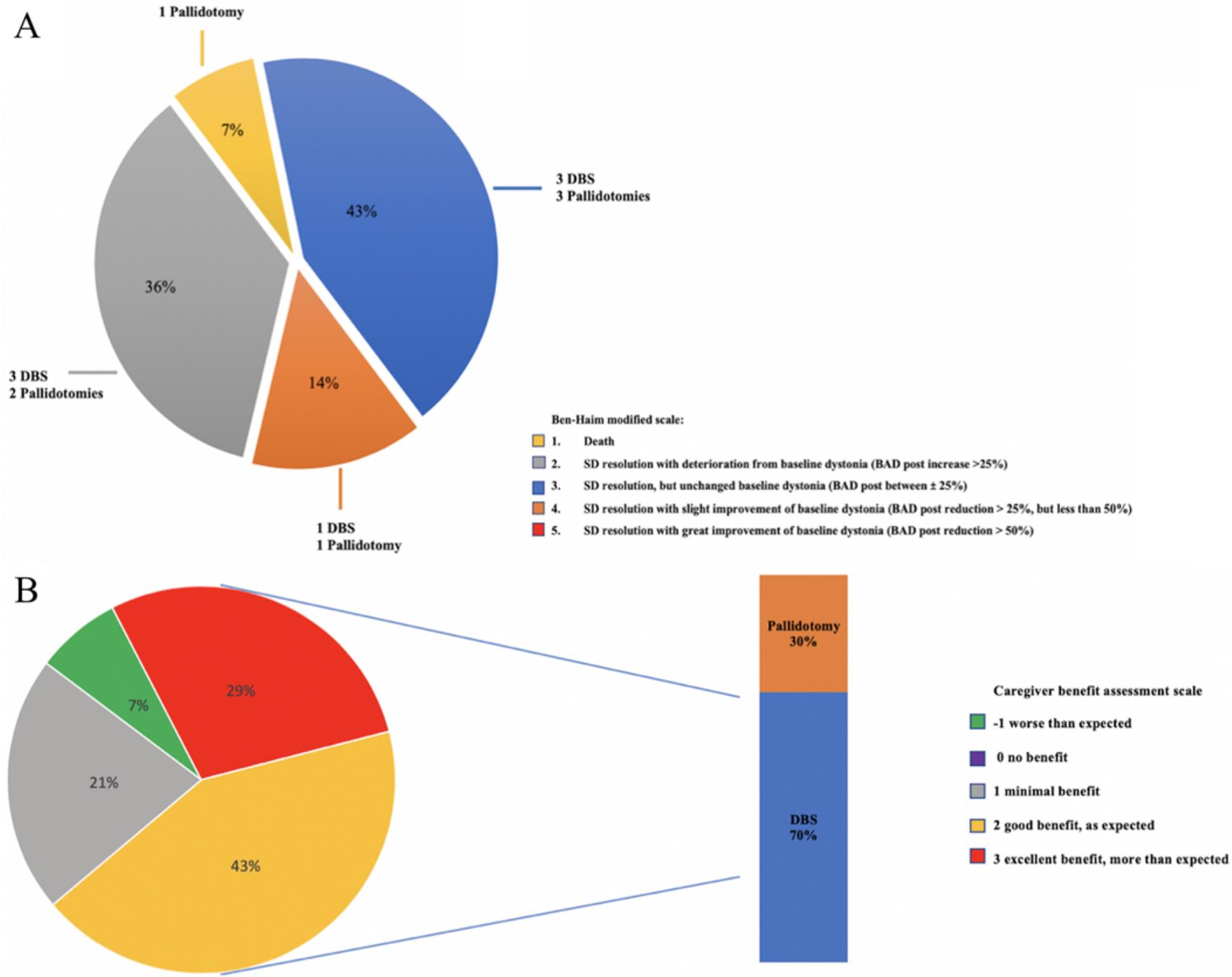

FIG. 1. A: Overall motor outcomes at the 1-month follow-up after surgery, categorized according to the modified Ben-Haim scale. B: A subjective assessment of the surgical procedures was administered to all caregivers during a telephone interview in June 2018 to capture potential easing of caregiving and increased patient comfort levels after surgery in the long term. Among the patients experiencing a good or excellent benefit (red and yellow), 70\% underwent DBS surgery. Figure is available in color online only.

the storm in $87.5 \%$ (7/8) of cases (Table 3). The mean SD resolution time among these patients was $34.8 \pm 19$ days. Stimulation was usually started 2 days after surgery, set at the following parameters: double monopolar symmetric stimulation (case+, 1-, 2-), 2.5-4 V, 60-90 $\mu \mathrm{sec}$, and $130-185 \mathrm{~Hz}$.

After 6 months, 1 patient showed a progressive slight dystonia worsening. After a readjustment of stimulation parameters, the patient's condition immediately improved, and dystonia returned to its baseline characteristics in a few days. In another patient, GPi DBS provided no benefit at all. She then underwent rescue conventional pallidotomy with SD regression.

No immediate postoperative adverse events were observed following DBS surgery, but there were a few hardware-related complications during the long-term followup. Three patients (3/8 [37.5\%]) had fatigue fracture of the right extracranial lead. They showed acute worsening of the baseline dystonia and consequently underwent urgent lead replacement.

\section{Pallidotomy}

Pallidotomy was the first surgical option in 6 patients (Table 3). Of these, 5 underwent conventional bilateral pallidotomy and 1 had bilateral SP. Pallidotomy interrupted SD in 5 patients $(5 / 6$ [83.3\%]) and was ineffective in 1 patient who eventually died after 1 month. Resolution of the storm among these patients took a mean $21.8 \pm 20.2$ days. No further neurological deficits or complications were observed after the surgeries. In addition, 1 patient successfully underwent pallidotomy as a last-resort treatment after GPi DBS failure.

\section{DBS Versus Pallidotomy}

Repeated measures ANOVA showed no significant dif- 


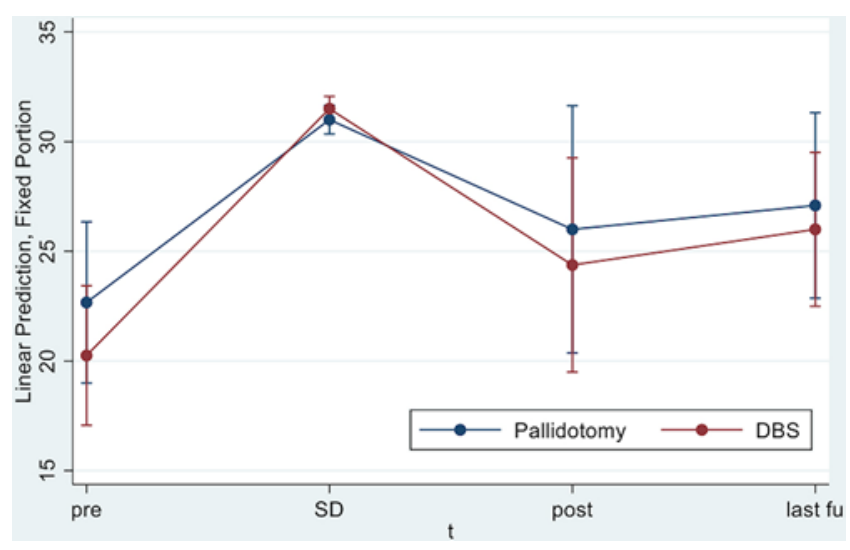

FIG. 2. Repeated measures ANOVA of BAD scores (y-axis) showing no significant differences between the surgical procedures $(p>0.05)$. $f u=$ follow-up; pre = preoperatively; post = postoperatively. Figure is available in color online only.

ference in BAD scores between the DBS and pallidotomy groups ( $p$ for interaction term $>0.05$; Fig. 2). Similarly, no significant differences were observed between the two techniques in terms of failure rates (risk difference DBS vs pallidotomy $-0.03,95 \% \mathrm{CI}-0.36$ to 0.30 ) or in terms of SD resolution time after surgery (DBS $34.8 \pm 19$ days, pallidotomy $21.8 \pm 20.2$ days, $\mathrm{p}>0.05$ )

\section{Postoperative Lead and Lesion Localization}

The mean stereotactic atlas coordinates in relation to the midcommissural point confirmed that lesions were usually located slightly anteromedially as compared to the lead location (Fig. 3). All 16 DBS leads were successfully localized in the MNI space, and all cases had at least 1 contact within the border of the posteroventral GPi.

\section{Discussion}

\section{Review of the Literature}

As far as we know, this is the first single-center evaluation to report both GPi DBS and pallidotomy outcomes for the treatment of drug-resistant SD. To date, $30 \mathrm{GPi}$ DBS and 8 ablative pallidotomy procedures have been separately described as isolated case reports, with varying success rates (Table 4). ${ }^{2-4,6,7,11,14,19,21-23,28,30,34,40,41,44,45}$

Ablative procedures, such as thalamotomy and pallidotomy, were the first surgical treatments used in SD patients. ${ }^{37}$ In 1998, Manji et al. performed for the first time 2-stage ventrolateral thalamic nuclei lesioning in a 9-yearold boy with severe SD and a unilateral left thalamotomy in a 38-year-old woman affected by a prevalent right-sided severe postencephalitic hemidystonia. ${ }^{26}$ In subsequent years, pallidotomy was found to be effective in the treatment of L-dopa-induced dyskinesia in patients with advanced Parkinson's disease; thus, the main target of stereotactic ablative procedures shifted from the thalamus to the GPi in dystonic patients as well. ${ }^{9}$ Currently, a larger study on SD and pallidotomy has been reported by Marras et al., who described the indications, surgical strategy, and outcome of bilateral pallidotomy in 4 pediatric patients with secondary dystonia who developed sudden refrac-

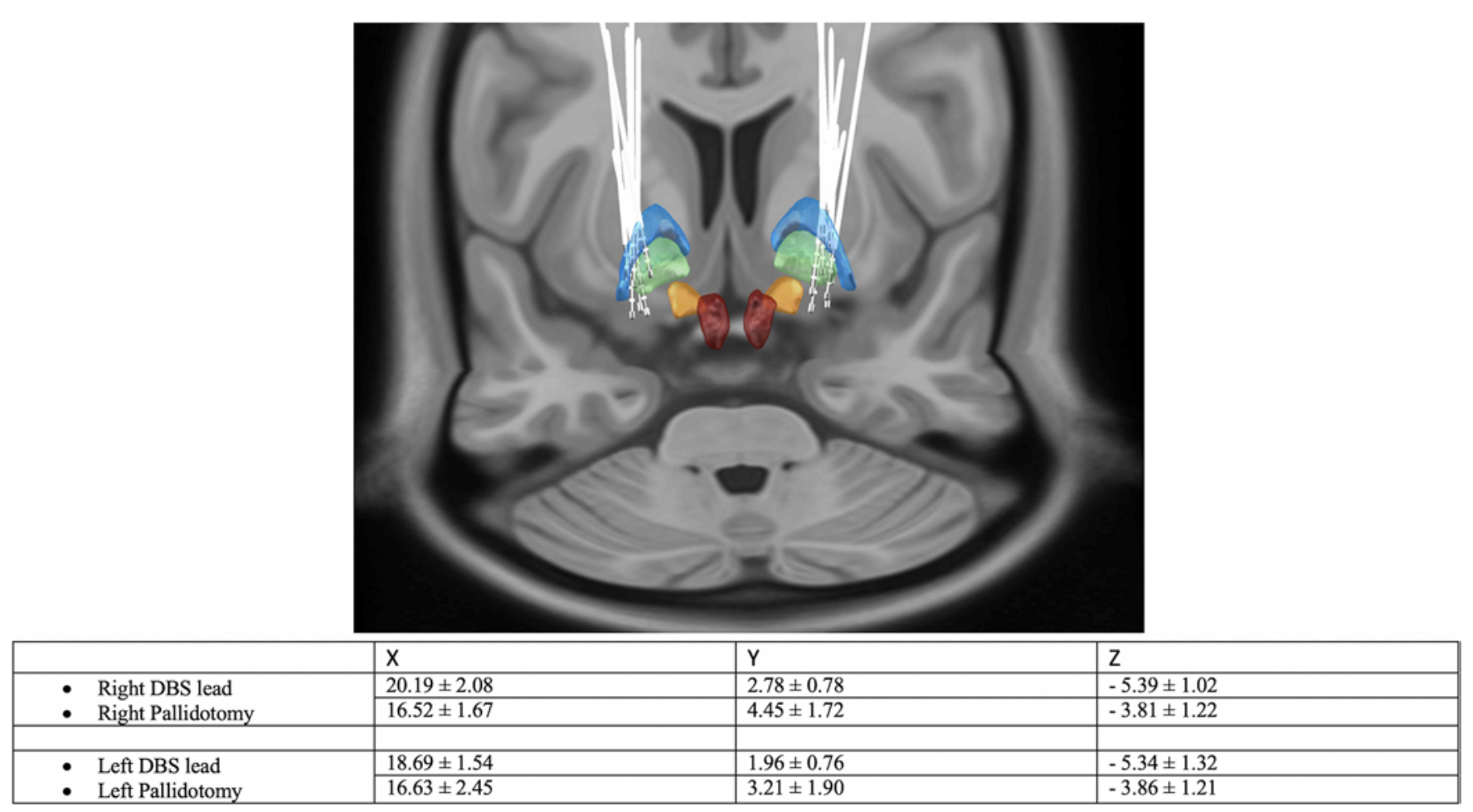

FIG. 3. Upper: Postoperative DBS lead locations in the MNI space. GPi, green; globus pallidus externus, blue; subthalamic nucleus, orange; red nucleus, red. Lower: DBS lead and pallidal lesion localizations in the AC-PC space. Figure is available in color online only. 


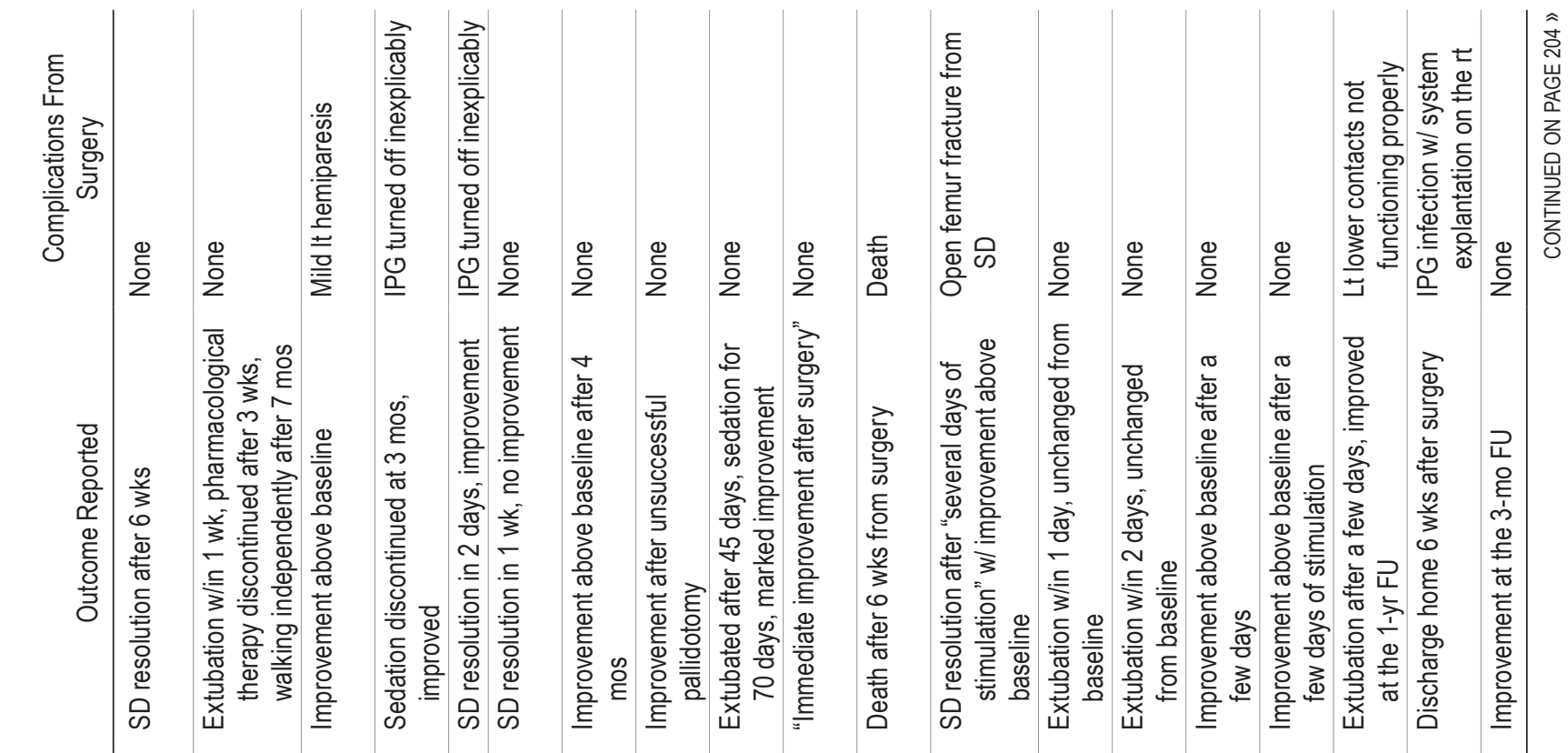

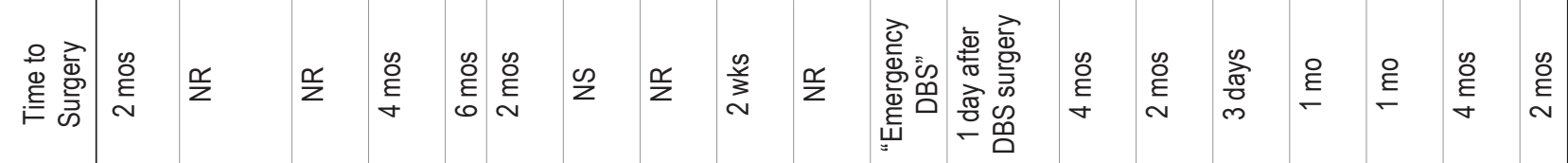

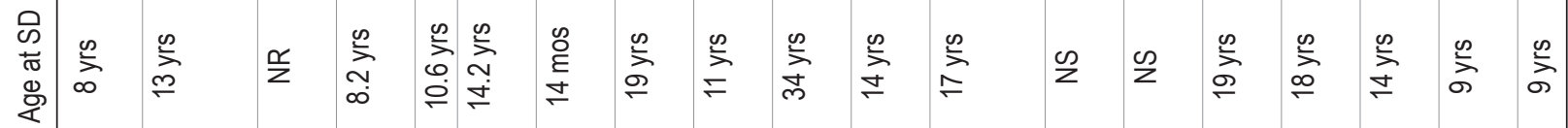

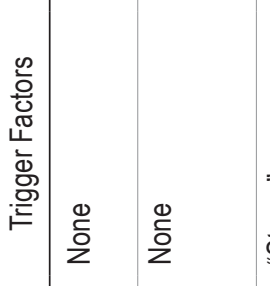

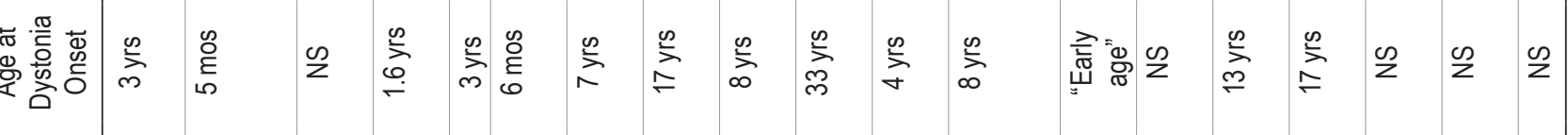

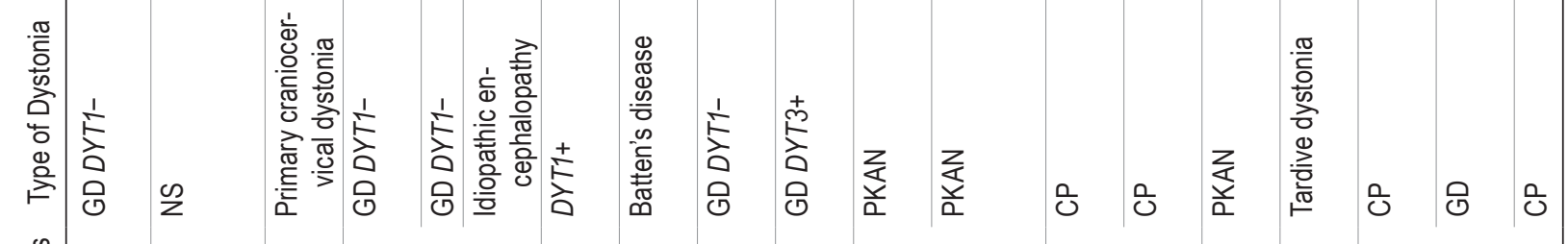

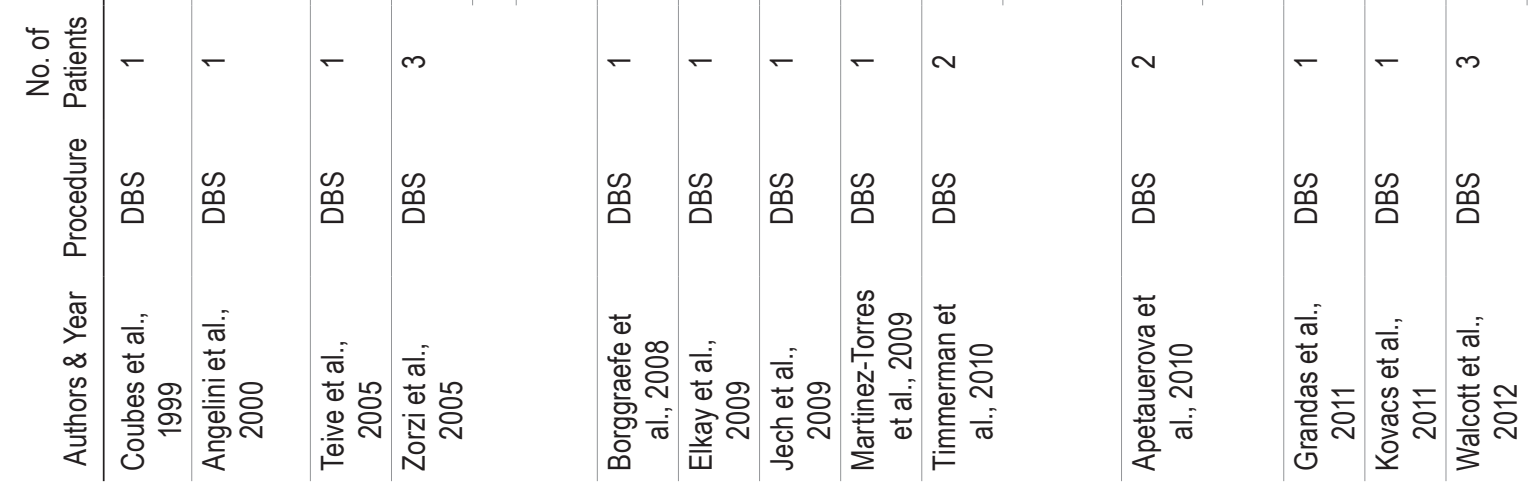




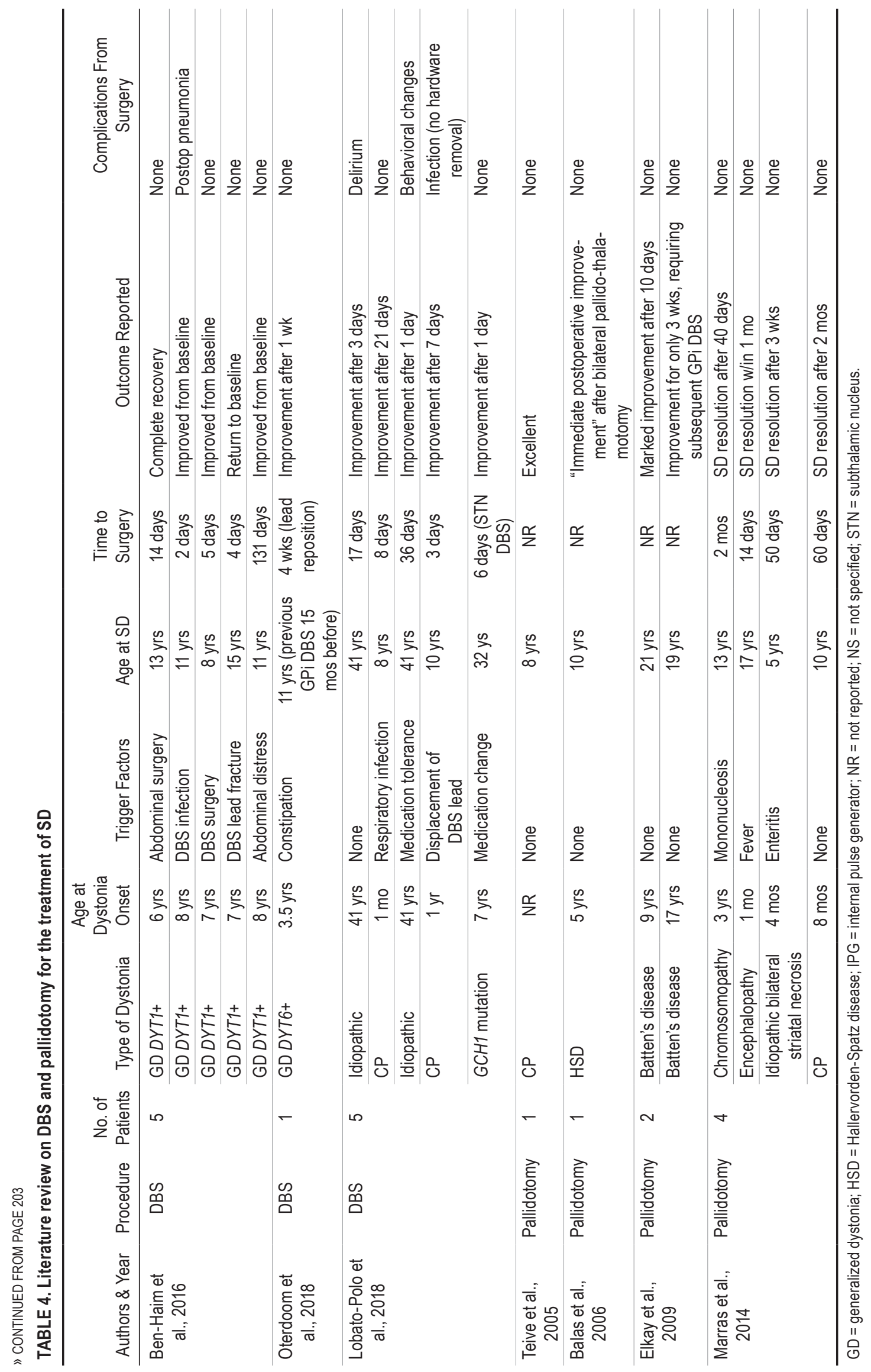


tory $\mathrm{SD} .^{28}$ In their series, pallidotomy was performed in the midportion of the GPi (X: 14-18, Y: 3-5, Z: -2) with progressive improvement of dystonia in all patients without any observed recurrence at a mean follow-up of 18.2 months. No postoperative complications were noted.

As with ablative surgical methods, the number of SD patients treated with GPi DBS is still limited. The first instance of bilateral GPi stimulation for SD was reported in 1996 by Philippe Coubes, who knew of the great efficacy of Laitinen's posteroventral pallidotomy for parkinsonian dyskinesias and thus proposed GPi stimulation as a compassionate intervention in an 8-year-old girl who had been in a complete refractory dystonic storm for several weeks. ${ }^{11}$ The striking result obtained by Coubes caused him to apply GPi DBS in 7 patients with DYT1 generalized dystonia, opening the way for the surgical treatment of many other types of dystonia. ${ }^{12}$ In 2016, a review by Ben-Haim et al. found that of the 28 SD patients described in the literature who had been treated with DBS or ablative surgery, 26 had cessation of their dystonic crisis with a return to baseline function and, in most cases, clinical improvement. ${ }^{6}$ Since then, a growing number of reports describing the effectiveness of DBS in cases of SD have been published because of the increased availability of the technique worldwide along with its great popularity for the treatment of other movement disorders, such as Parkinson disease and tremor (Table 4). Recently, Nerrant and colleagues retrospectively analyzed a cohort of 328 dystonia patients who had been seen over a period of 20 years. ${ }^{32}$ Twenty-five of these patients underwent de novo DBS to control an ongoing SD episode, with resolution in $92 \%$ of them, whereas 9 patients underwent subsequent lead implantation as rescue therapy while already benefiting from DBS, with a success rate of $91.3 \%$. Mortality as a direct consequence of an SD episode that was refractory to medical treatment and DBS was $10 \%$.

\section{Overall Efficacy of Surgery for the Treatment of Drug-Resistant SD}

In our series, the per-procedure success rate of surgery (86.7\% [13/15] success rate; 1 patient required salvage pallidotomy after DBS failure) was in line with rates previously reported in the literature on the subject. ${ }^{6,15}$ In addition, the positive effect of surgery was independent of the baseline dystonia duration and the time spent in SD before surgical intervention. In contrast with previously published experiences, only 2 patients in our study showed mild improvement in their baseline dystonic conditions, with dystonic conditions remaining unchanged or even worsening in the other patients (Fig. 1).,23 This difference in results may be due, in part, to the great heterogeneity of baseline dystonia traits or SD characteristics among studies. Follow-ups are also highly variable among studies, and only a few papers have reported long-term motor outcomes. Recently, Elkaim et al. showed that the grade of motor improvement is not very predictable after surgery for SD. ${ }^{13}$ Patients who had undergone surgical intervention, in fact, showed improvement compared to pre-SD baseline in $65.5 \%$ of cases, with the other cases $(34.5 \%)$ remaining unchanged or even worsening. These data are not negligible, especially if they are compared to the out- standing long-term surgical motor outcomes reported for the general dystonic population. ${ }^{31}$

In our opinion, SD should be considered more than a transient event overlapping the baseline dystonia. It may be indicative of an evolution of the disease causing high instability of the basal ganglia-cortical network, which is hard to revert.

Given our data, DBS or pallidotomy seems to be effective in down-regulating this instability in the acute phase of SD but with poor results in the long term. Why this happens is difficult to explain. In our opinion, this question may find an exhaustive answer only after collecting a large amount of electrophysiological data on SD, allowing those in the field to better understand the complex and still unknown pathophysiology of the disease. In order to do this, however, considering the rarity of the disease, international cooperation among multiple centers is of paramount importance.

\section{DBS Versus Pallidotomy}

Bilateral GPi DBS and pallidotomy were successful in $87.5 \%$ and $83.3 \%$ of SD cases, respectively. In terms of postoperative BAD values, no significant differences were found between the two techniques. Pallidotomy resulted in a shorter time to SD resolution than that following DBS (21.8 \pm 20.2 and $34.8 \pm 19$ days, respectively); however, the difference between the two techniques in this regard was not significant, although it nevertheless seems reasonable. DBS is, in fact, a pure neuromodulation technique that reestablishes neuronal networks' electrical stability over time. It is well known, for instance, that the effect of DBS in uncomplicated dystonia usually takes weeks to months to appear. Conversely, pallidotomy may work by anatomically interrupting an unregulated and disruptive circuit, allowing the remaining structures and circuits to function more properly in a shorter time. ${ }^{38,43}$

Although both procedures were extremely safe in terms of intraoperative complications and postoperative neurological deficits, DBS was associated with an increased number of long-term hardware failures (37.5\%). This finding is not surprising given that pallidotomy does not require implantation of permanent devices.

With regard to the postoperative location of pallidal lesions, our data suggest that lesioning a slightly more anteromedial portion of the GPi is equally safe, feasible, and effective as the ablation of the classic posteroventral DBS target. In our opinion, these data may be of some utility in the future considering that new, minimally invasive lesioning techniques, such as focused ultrasound, could soon be applied to dystonia and SD as well.

DBS showed greater subjective benefit among caregivers than pallidotomy (good and excellent benefit with DBS $70 \%$, vs $30 \%$ with pallidotomy). However, these data should be considered with caution given that 3 deaths occurred in the pallidotomy group (1 directly related to SD and the other 2 from a severe form of pneumonia evolving into sepsis). In particular, the 2 deaths occurring during the follow-up period may have introduced an important bias influencing the final caregivers' evaluations. In addition, pallidotomy, as a permanent lesional procedure, may have raised unrealistic caregiver expectations. Finally, it is 
not possible to exclude the fact that the anteromedial location of the lesions generated adverse events that the motor scale score and clinical evaluations were unable to detect. All of these points are purely speculative, however, and the low numbers of our sample do not allow for any definitive conclusions in this respect.

\section{Study Limitations}

This study has several limitations because of the unusual features of the pathological condition considered. First, the retrospective and nonrandomized design of the study may have introduced several forms of bias. More severe forms of SD may have been treated only with pallidotomy rather than DBS, thus hampering pallidotomy outcomes. In addition, the two populations are not strictly comparable because the target chosen for DBS is different from the one used for pallidotomy. Pharmacological therapies attempted before surgery were quite heterogeneous, and this could have strongly influenced the outcome after DBS and pallidotomy. Another important limitation of the study is the small sample size, which did not allow us to reach adequate statistical power. This could have definitely biased our statistical analysis.

\section{Conclusions}

$\mathrm{SD}$ is a rare, life-threatening emergency that can complicate a wide range of pediatric and adult dystonias. In this context, both GPi DBS and pallidotomy are effective, safe, and life-saving therapies and should be proposed early in the treatment of SD. The choice between the two procedures, in our opinion, should be tailored on a caseby-case basis, depending on factors such as etiology and evolution pattern of the underlying dystonia and clinical conditions at the moment of SD onset.

\section{Acknowledgments}

We thank all the patients and their families who participated in this study.

\section{References}

1. Allen NM, Lin JP, Lynch T, King MD: Status dystonicus: a practice guide. Dev Med Child Neurol 56:105-112, 2014

2. Angelini L, Nardocci N, Estienne M, Conti C, Dones I, Broggi G: Life-threatening dystonia-dyskinesias in a child: successful treatment with bilateral pallidal stimulation. Mov Disord 15:1010-1012, 2000

3. Apetauerova D, Schirmer CM, Shils JL, Zani J, Arle JE: Successful bilateral deep brain stimulation of the globus pallidus internus for persistent status dystonicus and generalized chorea. J Neurosurg 113:634-638, 2010

4. Balas I, Kovacs N, Hollody K: Staged bilateral stereotactic pallidothalamotomy for life-threatening dystonia in a child with Hallervorden-Spatz disease. Mov Disord 21:82-85, 2006

5. Barbosa BJAP, Carra RB, Duarte KP, Godinho F, de Andrade DC, Teixeira MJ, et al: Bilateral subthalamic nucleus stimulation in refractory status dystonicus. J Neurol Sci 388:159-161, 2018

6. Ben-Haim S, Flatow V, Cheung T, Cho C, Tagliati M, Alterman RL: Deep brain stimulation for status dystonicus: a case series and review of the literature. Stereotact Funct Neurosurg 94:207-215, 2016
7. Borggraefe I, Boetzel K, Boehmer J, Berweck S, Mueller-Felber W, Mueller K, et al: Return to participation - significant improvement after bilateral pallidal stimulation in rapidly progressive DYT-1 dystonia. Neuropediatrics 39:239-242, 2008

8. Cif L, Coubes P: Historical developments in children's deep brain stimulation. Eur J Paediatr Neurol 21:109-117, 2017

9. Cif L, Hariz M: Seventy years of pallidotomy for movement disorders. Mov Disord 32:972-982, 2017 (Erratum in Mov Disord 32:1498, 2017)

10. Cohn MC, Hudgins PA, Sheppard SK, Starr PA, Bakay RA: Pre- and postoperative MR evaluation of stereotactic pallidotomy. AJNR Am J Neuroradiol 19:1075-1080, 1998

11. Coubes P, Echenne B, Roubertie A, Vayssière N, Tuffery S, Humbertclaude V, et al: [Treatment of early-onset generalized dystonia by chronic bilateral stimulation of the internal globus pallidus. Apropos of a case.] Neurochirurgie 45:139_ 144, 1999 (French)

12. Coubes P, Roubertie A, Vayssiere N, Hemm S, Echenne B: Treatment of DYT1-generalised dystonia by stimulation of the internal globus pallidus. Lancet 355:2220-2221, 2000

13. Elkaim LM, De Vloo P, Kalia SK, Lozano AM, Ibrahim GM: Deep brain stimulation for childhood dystonia: current evidence and emerging practice. Expert Rev Neurother 18:773-784, 2018

14. Elkay M, Silver K, Penn RD, Dalvi A: Dystonic storm due to Batten's disease treated with pallidotomy and deep brain stimulation. Mov Disord 24:1048-1053, 2009

15. Fasano A, Ricciardi L, Bentivoglio AR, Canavese C, Zorzi G, Petrovic I, et al: Status dystonicus: predictors of outcome and progression patterns of underlying disease. Mov Disord 27:783-788, 2012

16. Franzini A, Cordella R, Messina G, Marras CE, Romito LM, Albanese A, et al: Targeting the brain: considerations in 332 consecutive patients treated by deep brain stimulation (DBS) for severe neurological diseases. Neurol Sci 33:1285-1303, 2012

17. Franzini A, Franzini A, Levi V, Cordella R, Messina G: An unusual surgical indication for cerebral tuberculosis: status dystonicus. Case report. Acta Neurochir (Wien) 160:13551358,2018

18. Franzini A, Levi V, Franzini A, Dones I, Messina G: Staged pallidotomy: MRI and clinical follow-up in status dystonicus. Br J Neurosurg 33:184-187, 2019

19. Grandas F, Fernandez-Carballal C, Guzman-de-Villoria J, Ampuero I: Treatment of a dystonic storm with pallidal stimulation in a patient with PANK2 mutation. Mov Disord 26:921-922, 2011

20. Horn A, Kühn AA: Lead-DBS: a toolbox for deep brain stimulation electrode localizations and visualizations. Neuroimage 107:127-135, 2015

21. Jech R, Bares M, Urgosík D, Cerná O, Klement P, Adamovicová M, et al: Deep brain stimulation in acute management of status dystonicus. Mov Disord 24:2291-2292, 2009

22. Kovacs N, Balas I, Janszky J, Simon M, Fekete S, Komoly $\mathrm{S}$ : Status dystonicus in tardive dystonia successfully treated by bilateral deep brain stimulation. Clin Neurol Neurosurg 113:808-809, 2011

23. Lobato-Polo J, Ospina-Delgado D, Orrego-González E, Gómez-Castro JF, Orozco JL, Enriquez-Marulanda A: Deep brain stimulation surgery for status dystonicus: a singlecenter experience and literature review. World Neurosurg 114:e992-e1001, 2018

24. Lumsden DE, Allen NM: Rethinking status dystonicus: a welcome start to a challenging problem. Mov Disord 33:344, 2018

25. Lumsden DE, King MD, Allen NM: Status dystonicus in childhood. Curr Opin Pediatr 29:674-682, 2017

26. Manji H, Howard RS, Miller DH, Hirsch NP, Carr L, Bhatia 
$\mathrm{K}$, et al: Status dystonicus: the syndrome and its management. Brain 121:243-252, 1998 (Erratum in Brain 123[Pt 2]:419, 2000)

27. Mariotti P, Fasano A, Contarino MF, Della Marca G, Piastra M, Genovese O, et al: Management of status dystonicus: our experience and review of the literature. Mov Disord 22:963968,2007

28. Marras CE, Rizzi M, Cantonetti L, Rebessi E, De Benedictis A, Portaluri F, et al: Pallidotomy for medically refractory status dystonicus in childhood. Dev Med Child Neurol 56:649-656, 2014

29. Marsden CD, Marion MH, Quinn N: The treatment of severe dystonia in children and adults. J Neurol Neurosurg Psychiatry 47:1166-1173, 1984

30. Martinez-Torres I, Limousin P, Tisch S, Page R, Pinto A, Foltynie T, et al: Early and marked benefit with GPi DBS for Lubag syndrome presenting with rapidly progressive lifethreatening dystonia. Mov Disord 24:1710-1712, 2009

31. Meoni S, Fraix V, Castrioto A, Benabid AL, Seigneuret E, Vercueil L, et al: Pallidal deep brain stimulation for dystonia: a long term study. J Neurol Neurosurg Psychiatry 88:960967, 2017

32. Nerrant E, Gonzalez V, Milesi C, Vasques X, Ruge D, Roujeau T, et al: Deep brain stimulation treated dystonia-trajectory via status dystonicus. Mov Disord 33:1168-1173, 2018

33. Ondo WG, Desaloms JM, Jankovic J, Grossman RG: Pallidotomy for generalized dystonia. Mov Disord 13:693-698, 1998

34. Oterdoom DLM, van Egmond ME, Ascencao LC, van Dijk JMC, Saryyeva A, Beudel M, et al: Reversal of status dystonicus after relocation of pallidal electrodes in DYT6 generalized dystonia. Tremor Other Hyperkinet Mov (N Y) 8:530, 2018

35. Rohani M, Munhoz RP, Shahidi G, Parvaresh M, Miri S: Fatal status dystonicus in tardive dystonia due to depletion of deep brain stimulation's pulse generator. Brain Stimul 10:160-161, 2017

36. Sobstyl M, Ząbek M, Kmieć T, Sławek J, Budohoski KP: Status dystonicus due to internal pulse generator depletion in a patient with primary generalized dystonia. Mov Disord 29:188-189, 2014

37. Sobstyl MR, Sławek JW, Ząbek M: The neurosurgical treatment of patients in dystonic state - overview of the literature. Neurol Neurochir Pol 48:63-70, 2014

38. Starr PA, Rau GM, Davis V, Marks WJJ Jr, Ostrem JL, Simmons D, et al: Spontaneous pallidal neuronal activity in human dystonia: comparison with Parkinson's disease and normal macaque. J Neurophysiol 93:3165-3176, 2005
39. Stewart K, Harvey A, Johnston LM: A systematic review of scales to measure dystonia and choreoathetosis in children with dyskinetic cerebral palsy. Dev Med Child Neurol 59:786-795, 2017

40. Teive HAG, Munhoz RP, Souza MM, Antoniuk SA, Santos MLSF, Teixeira MJ, et al: Status dystonicus: study of five cases. Arq Neuropsiquiatr 63:26-29, 2005

41. Timmermann L, Pauls KAM, Wieland K, Jech R, Kurlemann $\mathrm{G}$, Sharma N, et al: Dystonia in neurodegeneration with brain iron accumulation: outcome of bilateral pallidal stimulation. Brain 133:701-712, 2010

42. Trezza A, Antonini A, Sganzerla EP, Landi A: Globus pallidus internus deep brain stimulation for the treatment of status dystonicus in tardive dystonia. Acta Neurochir (Wien) 158:1789-1791, 2016

43. Vitek JL, Chockkan V, Zhang JY, Kaneoke Y, Evatt M, DeLong MR, et al: Neuronal activity in the basal ganglia in patients with generalized dystonia and hemiballismus. Ann Neurol 46:22-35, 1999

44. Walcott BP, Nahed BV, Kahle KT, Duhaime AC, Sharma N, Eskandar EN: Deep brain stimulation for medically refractory life-threatening status dystonicus in children. J Neurosurg Pediatr 9:99-102, 2012

45. Zorzi G, Marras C, Nardocci N, Franzini A, Chiapparini L, Maccagnano E, et al: Stimulation of the globus pallidus internus for childhood-onset dystonia. Mov Disord 20:11941200,2005

\section{Disclosures}

Dr. Levi is a medical advisor at Newronika S.R.L. (neurostimulator manufacturer), but this activity is not relevant to the paper.

\section{Author Contributions}

Conception and design: Levi. Acquisition of data: Levi, Zorzi. Analysis and interpretation of data: Levi, Zorzi. Drafting the article: Levi. Critically revising the article: Zorzi, Messina, Romito, Tramacere, Dones, Nardocci, Franzini. Approved the final version of the manuscript on behalf of all authors: Levi. Statistical analysis: Tramacere.

\section{Correspondence}

Vincenzo Levi: Fondazione IRCCS Istituto Neurologico Carlo Besta, Milan, Italy. vincenzo.levi@istituto-besta.it. 